\title{
A study for efficacy and safety of ferric carboxymaltose versus iron sucrose in iron deficiency anemia among pregnant women in tertiary care hospital
}

\section{Divyani Agrawal, Deepa Lokwani Masand*}

Department of Obstetrics and Gynecology, National Institute of Medical Sciences and Research Hospital, Jaipur, Rajasthan, India

Received: 14 March 2019

Accepted: 14 May 2019

\section{*Correspondence:}

Dr. Deepa Lokwani Masand,

E-mail: masand_deepa3@rediffmail.com

Copyright: () the author(s), publisher and licensee Medip Academy. This is an open-access article distributed under the terms of the Creative Commons Attribution Non-Commercial License, which permits unrestricted non-commercial use, distribution, and reproduction in any medium, provided the original work is properly cited.

\section{ABSTRACT}

Background: Anemia is one of the common manageable problem among the pregnant women worldwide, which contributes to maternal and perinatal mortality. This study aims to compare the efficacy and safety of intravenous ferric carboxymaltose with intravenous iron sucrose in treating anemia during pregnancy. Objective of this study was to compare safety and efficacy of intravenous ferric carboxymaltose with intravenous ferric sucrose in iron deficiency anemia during pregnancy.

Methods: It's an interventional prospective study conducted in Department of Obstetrics and Gynecology at NIMS, Jaipur, Rajasthan, India constituting of 100 pregnant women. Group 1- 50 pregnant women were treated with intravenous ferric carboxymaltose and Group 2: 50 pregnant women were treated with intravenous iron sucrose. Hemoglobin and serum ferritin levels were measured pre and post treatment with parenteral iron therapy. The efficacy of intravenous ferric carboxymaltose in comparison to intravenous iron sucrose was assessed. The evaluation of safety and tolerance with the parenteral therapy was also performed.

Results: Anemia during pregnancy was more prevalent among the reproductive age group and in multiparous women. The mean rise in the hemoglobin level with ferric carboxymaltose was $2.92 \mathrm{gm} / \mathrm{dl}$ and with that of iron, sucrose was $1.08 \mathrm{gm} / \mathrm{dl}$. The man rise in the serum ferritin levels with ferric carboxymaltose was $64.97 \mathrm{ng} / \mathrm{ml}$ and with iron sucrose was $31.64 \mathrm{ng} / \mathrm{ml}$. Ferric carboxymaltose was observed to be safer with no adverse events in comparison to the Iron sucrose which was related with adverse events among 03 pregnant women.

Conclusions: Intravenous ferric carboxymaltose was more efficacious and safer in comparison to intravenous iron sucrose among pregnant women. Hence, ferric carboxymaltose is the drug of choice in treatment of iron deficiency anemia during pregnancy.

Keywords: Hemoglobin, Intravenous ferric carboxymaltose, Intravenous iron sucrose, Serum ferritin

\section{INTRODUCTION}

Anemia during pregnancy is one of the most common issue encountered both in developing and developed areas. ${ }^{1}$ Among anemia, Iron deficiency anemia is the most common with significant effect over physical status. ${ }^{2}$ The prevalence pertaining to anemia in pregnancy is $33-89 \%$ and incidence being $42 \%$ (WHO, 2015)..$^{1,2}$ In developing countries it accounts to $40 \%$ maternal deaths among which $25 \%$ is for direct causation. ${ }^{2}$ Among nonpregnant the incidence is $53 \%$ (NHS-3). ${ }^{2,3}$ As per ICMR $2010,87 \%$ pregnant women are anemic out of which $10 \%$ have severe anemia. As per NFHS-2, $46 \%$ of urban women are anemic. ${ }^{3}$ 
According to WHO, anemia in pregnancy has been defined as haemoglobin $(\mathrm{Hb})$ levels $<11 \mathrm{gm} \%$ and hematocrit $<33 \% .^{4}$ Anemia in pregnancy as per $\mathrm{CDC}$ (centre of disease control and prevention) defined as $\mathrm{Hb}<10.5$ gm $\%$ during $1^{\text {st }}$ and $3^{\text {rd }}$ trimesters and $\mathrm{Hb}<11$ gm $\%$ during $2^{\text {nd }}$ trimester., ${ }^{3,4}$ ICMR (Indian medical council and research ) has categorized anemia during pregnancy as - mild- $\mathrm{Hb}-10-10.9$ gm\%, moderate- Hb-79.9 gm\%, severe- Hb-4-6.9 gm\%, very severe-Hb <4 $\mathrm{gm} \% .^{5}$

Anemia during pregnancy in India contributes as cause to $20 \%$ maternal death directly and $50 \%$ for associated causation..$^{5}$ The important consequences of moderate to severe anemia during pregnancy has susceptibility towards infection, Intrauterine growth retardation, premature delivery, increased perinatal morbidity and mortality. ${ }^{6}$ Also during delivery the requirement for blood transfusion increases with increase in cardiovascular complications, longer hospital stay, reduced lactation, and postpartum mood disorders. ${ }^{5,6}$

Aetiology for anemia are nutritional intake deficit, strict vegetarian diet, repeated pregnancies or pregnancy losses at very short intervals, pregnant females not taking supplementary medications, chronic blood loss like in malaria, hookworm infestation, hemorrhoids, iatrogenic, cancers, suppressed bone marrow erythropoiesis, renal related, autoimmune disease, trauma or ruptures, unknown. ${ }^{7}$ Clinically anemia is manifested with easy fatigueness, breathlessness, palpitation, giddiness, concentration deprivement, depression, decreased overall mental, physical and cognitive related performance with skin and mucosal pallor on examination. ${ }^{6,7}$ For diagnosing anemia low ferritin levels is considered as gold standard along with the lower $\mathrm{Hb}$ concentration. ${ }^{8}$

Requirement for Erythropoiesis includes iron, folic acid, vitamin B12, vitamin C, amino acids, traces of Zinc, and erythropoietin. ${ }^{7,8}$ Pregnancy is high iron demanding status with average of $1000 \mathrm{mg}$ in typical singleton pregnancy $(-$ $500 \mathrm{mg}$ for maternal $\mathrm{Hb}$ increment, $\sim 300 \mathrm{mg}$ for foetus and placenta, $200 \mathrm{mg}$ for wastage from body via gut, skin, urine, etc.). ${ }^{8}$ National Nutritional anemia control programme (NNARCP) was implemented in India, 1970 recommended for pregnant women iron tablet one per day for 100 days after the $1^{\text {st }}$ trimester $(1 \mathrm{tab}=100 \mathrm{mg}$ elemental iron and $500 \mathrm{mcg}$ folic acid). ${ }^{9}$

Parenteral iron therapy is more compliant, efficacious, better tolerance, rapid replenishment of iron stores and hence used in chronic blood loss, gastrointestinal disorders, impaired iron absorption. ${ }^{9,10}$ Type I complex have high incidence of anaphylaxis with slow release of iron, type II complexes are comparatively safer, type III complexes are unstable and leads to tissue toxicity. ${ }^{10}$

Iron sucrose (FeS) in Nov, 2000 got FDA approved forming iron hydroxide sucrose complex in water with 34000-60000 Dalton molecular weight. ${ }^{11}$ It is administered as intravenous bolus injection over 5-10 minutes or as infusion in $100 \mathrm{ml}$ normal saline over $15-20$ mins with no test dose and maximum daily dosage of 200 $\mathrm{mg}$, not more than thrice a week. ${ }^{3,9}$ Side effects includes metallic taste, nausea, dizziness, and local irritation. ${ }^{11,12}$

Ferric carboxymaltose (FCM) is novel non-dextran with type I complex administered rapidly $500 \mathrm{mg}$ in $100 \mathrm{ml} \mathrm{NS}$ over 6 mins and 1000-1500 mg in $250 \mathrm{ml}$ NS over 15 mins as intravenous infusion. ${ }^{12}$ It has faster controlled delivery raising $\mathrm{Hb}$ and replenishing iron stores at shorter duration with minimal toxicity and anaphylaxis have wider therapeutic index, better compliance and tolerance. ${ }^{12,13}$

The aim and objective of our present study is to compare safety and efficacy of intravenous ferric carboxymaltose with intravenous ferric sucrose in iron deficiency anemia during pregnancy.

\section{METHODS}

This was an interventional prospective study conducted among 100 pregnant women visiting in department of obstetrics and gynecology at National Institute of Medical Science and Research, Jaipur, Rajasthan, India from August 2018 to January 2019. Ethical clearance was taken from Institutional Committee following which detailed demographic and clinical details were taken from patients fulfilling the selection criteria, and a valid written consent was obtained. This Study includes all pregnant women from gestational age 20 weeks to 36 weeks irrespective of the obstetric score, with intolerance to oral therapy, $\mathrm{Hb}<11 \mathrm{gm} \%$ and serum ferritin levels $<30 \mathrm{ng} / \mathrm{ml}$. Exclusion criteria includes women with anaphylaxis to iron substitutes, hypertensive, any cardiac, renal or hepatic disease, any endocrine disease, anemia due to chronic disease and worm infestation. Upon clinical examination, skin and mucosal pallor was noted and investigations which were evaluated included complete blood count, peripheral blood smear and serum ferritin levels. The subjects were randomised and divided into 2 groups with each of 50 pregnant women with iron deficiency anemia.

- Group 1: received intravenous iron sucrose (200mg on alternate day, maximum- $600 \mathrm{mg} /$ week),

- Group 2: received intravenous ferric carboxymaltose (1000 mg/week).

The iron replenishment dosage was calculated by using Ganzoni’s Formula,

Total iron dose $=(($ Body weight $)(\mathrm{kg}) \times($ Target $\mathrm{Hb}-$ Actual $\mathrm{Hb})[\mathrm{g} / \mathrm{L})) \times 0.24+$ Iron stores $(\mathrm{mg})$ where, 0.24 is a correction factor that takes into account the patient's blood volume, estimated at $7 \%$ of body weight and $\mathrm{Hb}$ iron content, which is $0.34 \%$. 
Iron stores $=15 \mathrm{mg} / \mathrm{kg}$ in body weight $<35 \mathrm{~kg}$ and $500 \mathrm{mg}$ in body weight $>35 \mathrm{~kg}$.

Target hemoglobin post correction as per WHO is maximum $11 \mathrm{~g} / \mathrm{dl}$ during pregnancy.

Parenteral iron therapy along with oral nutrients was administered under doctor's supervision. The patients were then followed up after 3 weeks for increased $\mathrm{Hb}$ based on same parameters as previously mentioned (hemoglobin levels and serum ferritin).

\section{Statistical analysis}

The statistical analysis was done by Statistical Package for Social science (SPSS). Pictorial depiction, tables and graphs, percentages, mean, $\mathrm{t}$ test was also used with $5 \%$ level of significance.

\section{RESULTS}

From Table 1 it's observed to have higher incidence among the reproductive age group especially in pregnant women of 21-25 years of age. With the increase in the age its seen to have lesser prevalence of anemia.

Generally, the Indian population at rural conceive at younger age group who are vulnerable to anemia.

Table 1: Distribution according to age.

\begin{tabular}{|ll|}
\hline Age (years) & No. of women \\
\hline$<20$ & 12 \\
\hline $21-25$ & 56 \\
\hline $26-30$ & 22 \\
\hline $31-35$ & 8 \\
\hline $36-40$ & 1 \\
\hline$>40$ & 1 \\
\hline
\end{tabular}

Table 2: Distribution according to severity of anemia.

\begin{tabular}{|lll|}
\hline $\begin{array}{l}\text { Anemia } \\
\text { severity }\end{array}$ & Hb level in gm/dl & $\begin{array}{l}\text { No. of women } \\
\text { (Total=100) }\end{array}$ \\
\hline Mild & $10-10.9 \mathrm{gm} / \mathrm{dl}$ & 12 \\
\hline Moderate & $7-9.9 \mathrm{gm} / \mathrm{dl}$ & 86 \\
\hline Severe & $4-6.9 \mathrm{gm} / \mathrm{dl}$ & 2 \\
\hline
\end{tabular}

Table 2 depicts the prevalence of moderate anemia i.e haemoglobin levels of $7.9-9 \mathrm{gm} / \mathrm{dl}$ is higher $(86 \%$ of pregnant women). Nutritional deficiency is one of the most important cause in causation. Severe anemia i.e haemoglobin levels of 4-6.9 g/dl was noted in 2 pregnant women at time of this study.

Table 3: Prevalence of IDA depending on parity.

\begin{tabular}{|ll|}
\hline Parity & $\begin{array}{l}\text { No. of pregnant women with IDA } \\
\text { (total=100) }\end{array}$ \\
\hline Primigravida & 36 \\
\hline Multigravida & 64 \\
\hline
\end{tabular}

Table 3 infers that multiparous pregnant females (64\%) are more vulnerable to manifest iron deficiency anemia during pregnancy than in comparison to primigravida $(36 \%)$. The reason like less interspacing between pregnancies, economical burden, self-negligence lead to higher prevalence among the multigravida.

Table 4: Number of doses administered.

\begin{tabular}{|lll|}
\hline $\begin{array}{l}\text { No of doses } \\
\text { (vials) }\end{array}$ & $\begin{array}{l}\text { Iron sucrose } \\
(\mathbf{2 0 0} \mathbf{m g} / \text { dose })\end{array}$ & $\begin{array}{l}\text { Ferrous carboxy- } \\
\text { maltose (1000 } \mathbf{m g} / \text { dose })\end{array}$ \\
\hline $1-3$ & 12 & 49 \\
\hline $4-6$ & 37 & 01 \\
\hline$>6$ & 01 & 00 \\
\hline
\end{tabular}

As per Table 4, the doses requirement for treatment of iron deficiency anemia is lesser with ferric carboxymaltose in comparison to iron sucrose. Mild anemia improvised with lesser dosage than required to supplement iron in moderate iron. 1 case of severe anemia was treated with iron sucrose requiring 9 doses while the $2^{\text {nd }}$ case of severe anemia was treated with ferric carboxymaltose which needed 4 doses.

According to Table 5, the mean rise of hemoglobin was higher with ferric carboxymaltose $(2.92 \mathrm{gm} / \mathrm{dl})$ than iron sucrose $(1.08 \mathrm{gm} / \mathrm{dl})$. The mean rise in serum ferritin levels with ferric carboxymaltose $(64.97 \mathrm{ng} / \mathrm{dl})$ was higher than iron sucrose $(31.64 \mathrm{ng} / \mathrm{dl})$. With ferric carboxymaltose much rise in both haemoglobin and $\mathrm{Sr}$, ferritin was observed with lesser doses in comparison to the iron sucrose. Table 6 showed to have adverse effects with Iron sucrose than with administration of ferric carboxymaltose. 3 cases had adverse reaction wherein 1 case had local reaction in the form of forearm swelling with pruritus and 2 cases had systemic reaction of rashes and breathlessness.

Table 5: Laboratory parameter.

\begin{tabular}{|lllllll|}
\hline Variables & Iron Sucrose & & & \multicolumn{2}{c|}{ Ferrous carboxymaltose } \\
& Pre value (avg) & Post value (avg) & P value & Pre value (avg) & Post valve (avg) & P value \\
\hline HB & $8.06 \mathrm{~g} / \mathrm{dl}$ & $9.14 \mathrm{~g} / \mathrm{dl}$ & $<0.05$ & $8.05 \mathrm{~g} / \mathrm{dl}$ & $10.97 \mathrm{~g} / \mathrm{dl}$ & $<0.05$ \\
\hline Sr Ferritin & $25.86 \mathrm{ng} / \mathrm{ml}$ & $57.5 \mathrm{ng} / \mathrm{ml}$ & $<0.05$ & $29.93 \mathrm{ng} / \mathrm{ml}$ & $94.9 \mathrm{ng} / \mathrm{ml}$ & $<0.05$ \\
\hline
\end{tabular}


Table 6: Adverse effects.

\begin{tabular}{|lll|}
\hline Adverse reactions & IS & FCM \\
\hline Local reaction & 01 & 00 \\
\hline Systemic reaction & 02 & 00 \\
\hline Adverse event (total) & 03 & 00 \\
\hline
\end{tabular}

\section{DISCUSSION}

Anemia in the pregnant women is a serious global health concern. $^{1-3}$ As per WHO, about 32.4 million pregnant women suffer with anemia out of which 0.8 million are severely anemic. ${ }^{2,4} 50 \%$ anemic cases are attributable to iron deficiency anemia., ${ }^{4,5}$ IDA during pregnancy increases the risk of low birth weight, preterm labour, maternal and perinatal mortality with poor Apgar score. ${ }^{5}$ WHO estimated about 591000 perinatal deaths and 1150000 maternal deaths globally due to IDA directly or indirectly. ${ }^{1}$

Maternal mortality increases if anemic mothers have postpartum haemorrhage. ${ }^{11,12}$ Anemia below $8 \mathrm{~g} \%$ doubles the risk of infection and increases maternal morbidity when hb $<5$ gm\%. ${ }^{12-14}$ Estimated maternal deaths due to IDA in India is approximately 326000 and associated DALYs (Disability adjusted life years) is $12497000.14,15$ IDA results in decrease in GDP (Gross domestic product) up to $4.05 \%$ in developing countries and $1.18 \%$ of India's GDP. ${ }^{14-17}$

In this study reproductive age group of 21-25years constituted the majority with 56 pregnant women. Pregnant women with multiparity (64\%) were more vulnerable than primigravida (36\%). IDA during pregnancy has increased risk with low socio-economic status, high parity, nutritional deficiencies, phylate rich Indian diets, malaria, helminth infections and inflammatory or infectious diseases..$^{12,14,16,18,23}$ The causes of anemia during pregnancy are low iron bioavailability in food, inadequate intake, excess coffee/tea, chronic infections, menstrual loss, worm infestation. ${ }^{10,18,21,23}$

In this study moderate anemia in pregnant women was more prevalent with $86 \%$ and 2 cases of severe anemia were also into the study. As per NFHS 2 and 3 and ICMR $70 \%$ of preschool children, pregnant women and adolescent girls are anemic. Hence, anemia begins at childhood, worsens during adolescence and aggravates during pregnancy. ${ }^{14,21-23}$

The routine medical practice comprised of oral iron and blood transfusion therapy that were associated with various adverse events and reactions. ${ }^{18-20}$ Also, surgically assisted deliveries leads to inflammation causing sequestration of iron stores in macrophages and decrease in intestinal absorption. ${ }^{20-22}$ This study was conducted for more efficient therapeutic medication as parenteral therapy. The study aimed to compare between intravenous iron sucrose and intravenous ferric carboxymaltose which is the newer drug approved for use in IDA during $2^{\text {nd }}$ and $3^{\text {rd }}$ trimester. Iron sucrose was given as $200 \mathrm{mg} /$ day on alternate days and ferric carboxymaltose as $1000 \mathrm{mg} /$ week up till the desired iron requirement for increase in hemoglobin levels. ${ }^{2,3,10,23}$ In the present study, number of required iron sucrose for desired requirement was 4-6 doses and >6 doses in 1 case of severe IDA. Ferric carboxymaltose was required in 1-3 doses and 4-6 doses in 1 case of severe IDA.

In the study conducted hemoglobin levels and serum ferritin levels were noted before and 3 weeks after the parenteral iron therapy. Iron sucrose raise the hemoglobin by $1.08 \mathrm{~g} \%$ and serum ferritin by $31.64 \mathrm{ug} / \mathrm{dl}$ in comparison to ferric carboxymaltose raising hemoglobin levels by $2.92 \mathrm{~g} \%$ and serum ferritin by $64.97 \mathrm{ug} / \mathrm{dl}$. Therefore, ferric carboxymaltose was more efficient and compliant in improving the IDA during the pregnancy. Even 2 cases of severe anemia were administered iron therapy and with both the formulation the pregnant women had raise in hemoglobin levels (ferric carboxymaltose required less number of doses than iron sucrose). The adverse events with ferric carboxymaltose were negotiable in comparison to iron sucrose which lead to local reaction like skin rashes in 1 case and systemic reactions like fever, chills, breathlessness, rashes in 3 cases of pregnant women with IDA.

This present study have its results in consistent with the other studies conducted worldwide i.e. Christoph et al, Froessler et al, Patel J et al, Garg R et al, Metgud MC et al, Boughton S et al, Joshi SD et al, Maheshwari et al, Mahajan A et al.

Christoph et al conducted a retrospective study on 206 pregnant women $(103=\mathrm{FCM}, 103=\mathrm{IS})$ which gave results of rise in hemoglobin by FCM $15.4 \mathrm{~g} \%$ and IS $11.7 \% .^{8}$ FCM was found more efficacious and safer than IS. ${ }^{8}$ Similarly Froessler et al, carried out prospective observational study in Australia with 65 anemic pregnant women who received FCM showing significant raise in baseline hemoglobin level. ${ }^{9}$ IDA during pregnancy is associated with low birth weight, intrauterine growth restriction (IUGR), intrauterine fetal death (IUFD), fetal distress, low Apgar score and increased perinatal mortality. ${ }^{37,11}$ These significantly occurs in women with mild maternal anemia, with 2 to 3 folds increase with moderate maternal anemia and 8 to 10 folds with $\mathrm{Hb}$ less -than $5 \mathrm{~g} \% .^{3,7,12}$ Lower iron stores in the IDA can cause poor mental performance or behavioural abnormalities in lately. ${ }^{2,14}$ Significant difference is present in the infants mean birth weight born to anemic and non-anemic mothers. ${ }^{3,13}$ Anemia in second trimester associated with preterm birth which increases by 5 folds in anemia due to iron deficiency and by 2 folds in anemia due to other causes. ${ }^{3,13,23}$ Hence, correction of iron deficiency anemia during pregnancy with parenteral therapy has role in better neonatal outcome with decreased perinatal mortality. 5,10 
Ferric carboxymaltose seems to be superior to other parenteral iron formulations due to its high efficacy, safety and compliance revolutionising the management of iron deficiency anemia during pregnancy. ${ }^{13,14,17,23}$ The disadvantage with ferric carboxymaltose is its high cost in comparison to other parenteral iron preparations, which is well compensated with lesser number of hospital visits and shorter duration of hospital stay. ${ }^{9,13}$ Therefore, it can be recommended as first line drug to decrease the burden and incidence of IDA during pregnancy.

\section{CONCLUSION}

Intravenous Iron sucrose and intravenous Ferric carboxymaltose both results in increase in the hemoglobin and serum ferritin levels. Ferric carboxymaltose is safer with better tolerance and efficacy among the pregnant women diagnosed with iron deficiency anemia than in comparison to iron sucrose. Ferric carboxymaltose.

Funding: No funding sources

Conflict of interest: None declared

Ethical approval: The study was approved by the Institutional Ethics Committee

\section{REFERENCES}

1. World Health Organization. Micronutrient deficiencies: prevention and control guidelines. Geneva: World Health Organization, 2015. Available at; https://www.who.int/nutrition/publications/ WHO_WFP_UNICEFstatement.pdf. (Accessed on December 2018).

2. FOGSI General Clinical Practice Recommendations. Management of iron deficiency anaemia in pregnancy. 2016; Available at; (http://www.fogsi.org/wp-content/uploads/2016/ 05/The- evidence-base_IDA-Pregnancy-24-May2016-Clean.pdf. (Accessed on December 2018).

3. Indian council of medical research evaluation of nutritional anaemia prophylaxis program task force study New Delhi; $1989 . \quad$ Available at; https://www.icmr.nic.in/sites/default/files/icmr_bulle tins/bufeb00.pdf. (Accessed on December 2018).

4. Centre for disease control (CDC), criteria for anaemia in children and child bearing age women MMWR. 1989;38:400-4; Available at; https://www.cdc.gov/MMWR/preview/mmwrhtml/0 0051880.htm. (Accessed on November 2018).

5. FOGSI General Clinical Practice Recommendations. Management of Iron Deficiency Anemia in Pregnancy. Available at; www.fogsi.org/wpcontent/uploads/2017/07/gcpr-recommendationida.pdf. (Accessed on January 2018).

6. Guidelines for Prevention of Maternal Anaemia. Available at; http://www.nrhmtn.gov.in/ guideline/RGPMA.pdf. (Accessed on December 2018).
7. Christoph P, Schuller C, Studer H, Irion O, De Tejada BM, Surbek D. Intravenous iron treatment in pregnancy: comparison of highdose ferric carboxymaltose vs. iron sucrose. J Perinatal Med. 2012;40(5):469-74.

8. Froessler B, Collingwood J, Hodyl NA, Dekker G. Intravenous ferric carboxymaltose for anaemia in pregnancy. BMC pregnancy and Childbirth. 2014;14:115.

9. Friedrisch JR, Cancado RD. Intravenous ferric carboxymaltose for the treatment of iron deficiency anaemia. Braz J Hem Hemother. 2015;37(6):400-5.

10. Zeba D. Intravenous iron treatment in pregnancy: ferric carboxymaltose for correction of iron deficiency anaemia Faridpur. Med Coll J. 2017;12(2):54-7.

11. Singh S, Dhama V, Chaudhary R, Singh P. Comparing the safety and efficacy of intravenous iron sucrose and intravenous ferric carboxymaltose in treating postpartum anemia. Int $\mathrm{J}$ Reprod Contracept Obstet Gynecol. 2016;5:1451-6.

12. Joshi SD, Chikkagowdra S, Kumar VCM. Comparative study of efficacy and safety of intravenous ferric carboxy maltose versus iron sucrose in treatment of postpartum iron deficiency anemia. Int J Reprod Contracept Obstet Gynecol. 2016;5.

13. Anand T, Rahi M, Sharma P, Ingle GK. Issues in prevention of iron deficiency anemia in India. Nutrition. 2014;30(7-8):764-70.

14. Institute of Medicine, Committee on Nutritional Status During Pregnancy and Lactation. Washington DC: National Academy press. 1990;272:98.

15. Lone FW, Qureshi RN, Emanuel F. Maternal anaemia and its impact on perinatal outcome in a tertiary care hospital in Pakistan. Eastern Mediterr Health J. 2004;10:801-7.

16. VanWyck DB, Martens MG, Seid MH, Baker JB, Mangione A. Intravenous ferric carboxymaltose compared with oral iron in the treatment of postpartum anaemia: a randomized controlled trial. Obstet Gynecol. 2007;110:267-78.

17. Breymann C, Gliga F, Bejenariu C, Strizhova N. Comparative efficacy and safety of intravenous ferric carboxymaltose in the treatment of postpartum iron deficiency anemia. Int $\mathbf{J}$ Gynaccol Obstct. 2008;101:67-73.

18. Pavord S, Myers B, Robinson S, Allard S, Strong J. UK guidelines on the management of iron deficiency in pregnancy. Br J Haematol. 2012;156:588-600.

19. Crosby WH. The rationale for treating iron deficiency anaemia. Arch Int Med. 1984;144:471-2.

20. Bhandal N, Russel R. Intravenous versus oral iron therapy for postpartum anaemia. BJOG. 2006;113(11):1248-52.

21. Bayoumeu F, Subiran-Buisset C, Baka NE, Legagneur H, Monnier-Barbarino P, Laxenaire MC. Iron therapy in iron deficiency anaemia in pregnancy: intravenous route versus oral route. Am J Obstet Gynaecol. 2002;186:518-22. 
22. Breymann C, Honegger C, Holzgreve W, Surbek D. Diagnosis and treatment of iron-deficiency anaemia during pregnancy and postpartum. Arch Gynecol Obstet. 2010;282:577-80.

23. Garg R, Nigam A, Agrawa IP, Nigam A, Agrawa IR. Iron carboxymaltose: A safe and effective molecule to combat anaemia in pregnancy. Int $\mathrm{J}$ Cur Res Aca Rev. 2016;4(2):124-30.
Cite this article as: Agrawal D, Masand DL. A study for efficacy and safety of ferric carboxymaltose versus iron sucrose in iron deficiency anemia among pregnant women in tertiary care hospital. Int $\mathbf{J}$ Reprod Contracept Obstet Gynecol 2019;8:2280-5. 